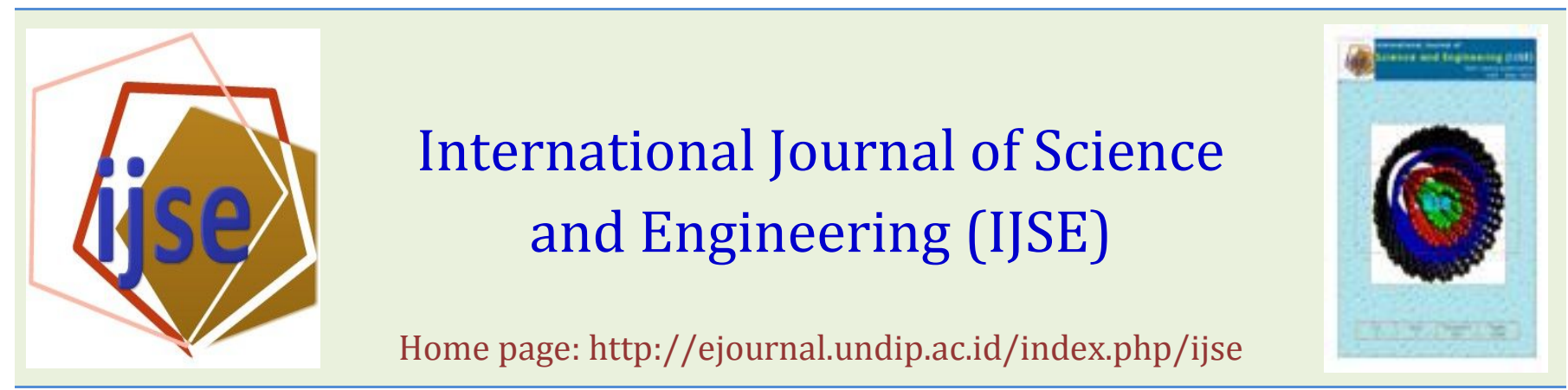

\title{
Characterization of activated carbon produced from urban organic waste
}

\author{
Abdul Gani Haji ${ }^{1}$, Gustan Pari², Muhammad Nazar ${ }^{1}$ and Habibati ${ }^{1}$ \\ ${ }^{1}$ Department of Chemistry, FKIP Syiah Kuala University, Darussalam, Banda Aceh 23111, Indonesia \\ ${ }^{2}$ Forest Product Research and Development Center, Bogor, Indonesia \\ Coorresponding Author: aganihaji@yahoo.com
}

\begin{abstract}
The difficulties to decompose organic waste can be handled naturally by pyrolisis so it can decomposes quickly that produces charcoal as the product. This study aims to investigate the characteristics of activated carbon from urban organic waste. Charcoal results of pyrolysis of organic waste activated with $\mathrm{KOH} 1.0 \mathrm{M}$ at a temperature of 700 and $800^{\circ} \mathrm{C}$ for 60 to 120 minutes. Characteristics of activated carbon were identified by Furrier Transform Infra Red (FTIR), Scanning Electron Microscopy (SEM), and X-Ray Diffraction (XRD). However, their quality is determined yield, moisture content, ash, fly substances, fixed carbon, and the power of adsorption of iodine and benzene. The identified functional groups on activated carbon, such as $0 \mathrm{H} \mathrm{(3448,5-3436,9}$ $\left.\mathrm{cm}^{-1}\right)$, and $\mathrm{C}=0\left(1639,4 \mathrm{~cm}^{-1}\right)$. In general, the degree and distance between the layers of active carbon crystallites produced activation in all treatments showed no significant difference. The pattern of activated carbon surface topography structure shows that the greater the pore formation in accordance with the temperature increase the more activation time needed. The yield of activated carbon obtained ranged from 72.04 to $82.75 \%$. The results of characterization properties of activated carbon was obtained from 1.11 to $5.41 \%$ water, 13.68 to $17.27 \%$ substance fly, 20.36 to $26.59 \%$ ash, and 56.14 to $62.31 \%$ of fixed carbon . Absorption of activated carbon was good enough at $800^{\circ} \mathrm{C}$ and 120 minutes of activation time, that was equal to $409.52 \mathrm{mg} / \mathrm{g}$ of iodine and $14.03 \%$ of benzene. Activated carbon produced has less good quality, because only the water content and flying substances that meet the standards.
\end{abstract}

Keywords - organic waste, carbonization, $\mathrm{KOH}$ activation, quality of activated carbon

Submission: September 17, 2013

Corrected : October 4, 2013

Accepted: October 11, 2013

Doi: 10.12777 ijse.5.2.89-94

[How to cite this article: Haji, A.G., Pari, G., Nazar, M., and Habibati. (2013). Characterization of activated carbon produced from urban organic waste . International Journal of Science and Engineering, 5(2),89-94. Doi: 10.12777/ijse.5.2.89-94]

\section{Introduction}

Organic waste has become a problem for society and government, this is due to the environmental pollution. Stated that organic waste can be divided into two types, namely easy to decompose organic waste (garbage) and that does not easily rot (Rubbish). Garbage is a bit wet solid waste, in the form of organic matter mainly comes from the agricultural sector. This waste is easily decomposed by microorganisms, because they have relatively short chemical chains. While Rubbish is a solid organic waste is decomposed by microorganisms is difficult because it has a relatively long chemical chains. Therefore, this waste is still causing serious problems for landfill managers to date. One way that may be the best solution for handling and/or processing of this waste, in particular by carbonization method.

Carbonisation is a process of incomplete combustion of materials containing carbon, both derived from plants, animals and minerals into charcoal (carbon). Generally the process of carbonisation took place at temperatures above $300^{\circ} \mathrm{C}$ within 4-7 hours [3]. But this situation is very dependent on raw materials and processing means. In the process of carbonization of various carbon materials through decomposition of organic molecules without air produced tar, light gases and a porous solid charcoal $[9,15]$.

There are so many benefits of composing solid organic waste into charcoal, particularly in suppressing the volume of landfill waste. Charcoal is not only 
beneficial as a source of energy but also potential to be developed with the activation method becomes activated carbon. Activated carbon is an amorphous carbon that consisting of carbon atoms in free and has an internal surface so that it has good capability in adsorption. The charcoal surface is still covered by hydrocarbon deposits that inhibit its activity, whereas the surface of activated carbon has been relatively free of deposits and able to absorb because of the surface area and has an open pore [8]. The research results of showed that the production of charcoal from mangrove wood raw material will be obtained higher yield by treatment of the sample by way of cut manually using a knife, compared with the ground using a mortar. The yield of the most highly activated carbon which is $77.39 \%$, found in mangroves, coconut shell and then $72.93 \%$, followed by Acacia mangium $66.28 \%, 57.89 \%$ and pines. Charcoal-making process can be done in two ways, chemically and physically [15].

Chemicals that have been used to activate the charcoal into charcoal, such as $\mathrm{NaOH}$ or $\mathrm{KOH}$ [5], $\mathrm{KOH}$ [19], $\mathrm{H}_{3} \mathrm{PO}_{4}$ [7], $\mathrm{H}_{2} \mathrm{SO}_{4}[10,14], \mathrm{HCl}$ [21], $\mathrm{HNO}_{3}$ [4], $\mathrm{Na}_{2} \mathrm{CO}_{3}$ and $\mathrm{K}_{2} \mathrm{CO}_{3}$ [12]. The use of chemicals as an activator material often resulted in discoloration of activated carbon produced.

Physical activation of charcoal using a weak oxidizing agent, such as $\mathrm{CO}_{2}$ gas, water vapor, nitrogen, and others [15]. Therefore, this process does not occur in the oxidation of carbon atoms compiler charcoal, but it only oxidizes oxidizing components which cover the surface of the porous charcoal. At temperatures below $800^{\circ} \mathrm{C}$, the activation process with steam or $\mathrm{CO}_{2}$ is very slow, while at temperatures above $1000^{\circ} \mathrm{C}$ will cause damage to the hexagonal lattice structure of charcoal. Some oxidizing gas which can be used for activation of charcoal in physics are water vapor $\left(\mathrm{H}_{2} \mathrm{O}\right)$ [1], $\mathrm{CO}_{2}$ or $\mathrm{N}_{2}$ [13], $\mathrm{H}_{2}$ [20], $\mathrm{Br}_{2}$ [6], and $\mathrm{CH}_{4}$ [17].

\section{Materials and Methods}

\section{Equipment and Materials}

The main material used is pyrolisized charcoal of solid organic waste from the city of Bogor, which consists of bamboo, wood, and twigs. Chemical used as an activator such as solution of $1 \mathrm{M} \mathrm{KOH}, \mathrm{KBr}$, gold pellets, $0.1 \mathrm{~N}$ iodine solution, $0.1 \mathrm{~N} \mathrm{Na}_{2} \mathrm{~S}_{2} \mathrm{O}_{3}$ solution, $1 \%$ starch solution, benzene, aluminum foil and distilled were used as characterization materials.

The main equipment used to produce activated carbon is electric retort as shown in Figure 1. The component consists of:

1. Retort made of stainless steel $100 \mathrm{~cm}$ and a diameter of $5 \mathrm{~cm}$, which is wound with nickel wire as a heating element;

2. Two thermocouples are provided for controlling the activation temperature;

3. The kettle is also made of stainless steel as a supplier of steam activator derived from materials used;

4. Condenser made of glass as a coolant, and

5. Pumpkin boiler made of pyrex glass to accommodate the distillate.

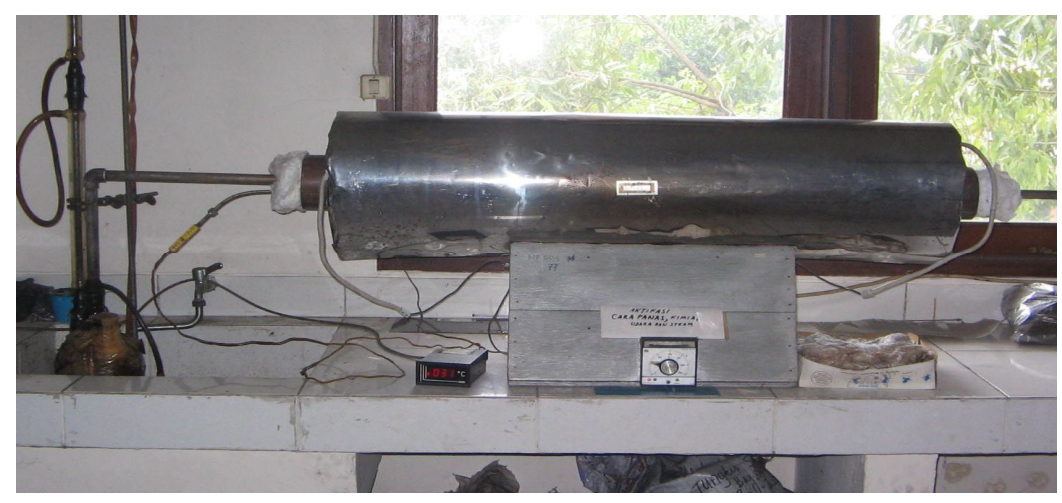

Figure 1. Retort carbonisation

Tools that used for characterization of activated carbon are analytical scales, ovens, porcelain cup, desiccators, electric furnace, the titration device, and glassware are common in chemistry labs, while the main tools used were FTIR spectrometer, SEM, and XRD.

\section{Procedure}

Charcoal-making procedures of the raw material of solid organic waste carbonisation using electric retort equipment (Figure 1) with the activator is $\mathrm{KOH} 1 \mathrm{M}$ as shown in Table 1.
Procedure for determining the quality of activated carbon based on the procedures [2] with the steps between the activated carbon produced in each treatment on the ground by using mortar and pestle, then filtered with activated carbon powder sized 100 mesh sieve. Furthermore, active charcoal powder were characterized according to the quality parameters including yield, moisture content, ash, fly substances, fixed carbon, and the power of sorption of iodine, and benzene. To determine the pattern of activated carbon structure was characterized by using instrument of FTIR, SEM, and XRD. 
Table 1. Combination treatment using activated carbon-making raw materials

\begin{tabular}{ccc}
\hline \multirow{2}{*}{ code } & \multicolumn{2}{c}{ Treatment } \\
\cline { 2 - 3 } & $\begin{array}{c}\text { Time } \\
(\text { minute) }\end{array}$ & $\begin{array}{c}\text { Temperature } \\
\left({ }^{\circ} \mathrm{C}\right)\end{array}$ \\
\hline W1S1 & 60 & 700 \\
W1S2 & 60 & 800 \\
W2S1 & 120 & 700 \\
W2S2 & 120 & 800 \\
\hline
\end{tabular}

Description: $\quad W 1=$ activation time 60 minutes

$\mathrm{W} 2$ = activation time 120 minutes

$\mathrm{S} 1=$ activation temperature of $700^{\circ} \mathrm{C}$

$\mathrm{S} 2=$ activation temperature at $800^{\circ} \mathrm{C}$

\section{Results and Discussion \\ Structure Identification of Activated carbon}

Results of analysis on the IR absorption spectra of activated carbon can give clues about changes in functional groups of compounds due to the influence of activator treatment such as time, temperature and interaction between these factors. IR absorption spectra of activated carbon with the activation of activator $\mathrm{KOH}$ 1.0 $\mathrm{M}$ is shown in Figure 2.

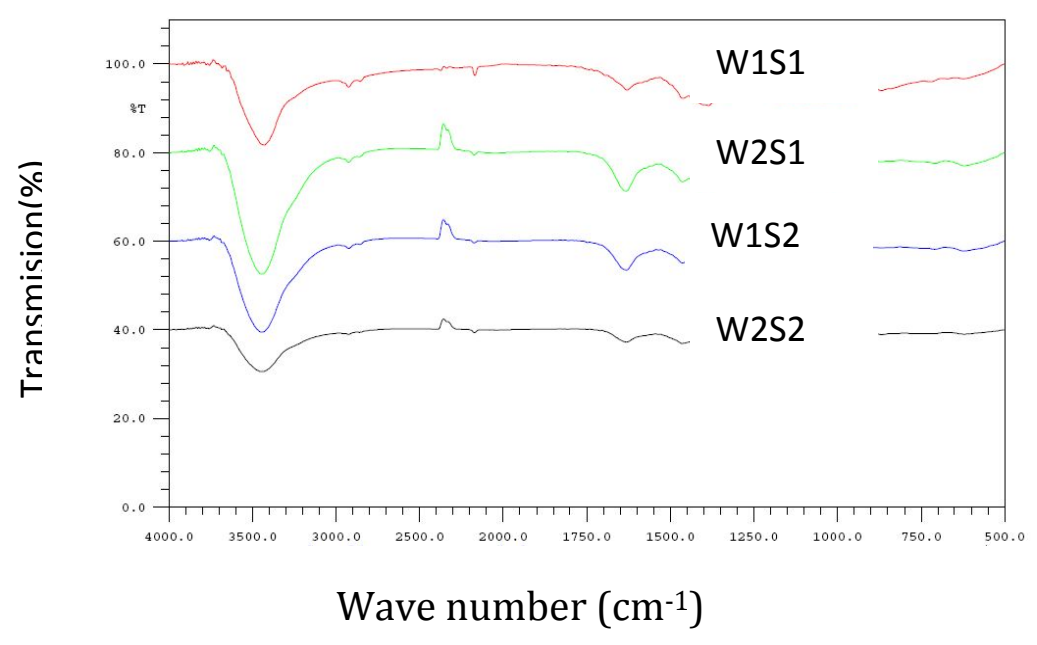

Figure 2. IR absorption spectra of activated carbon using KOH 1.0 M

Figure 2 shown that activated carbon tends to have the same adsorption area. But a stronger IR absorption in the vicinity of 1450.4 to $1427.2 \mathrm{~cm}^{-1}$ means that this treatment increases the concentration of $\mathrm{CH}$ of aliphatic compounds. In addition, all treatments also strengthen the presence of hydroxyl $(\mathrm{OH})$ as shown by no significant change in absorption bands in the region from 3444.6 to $3409.9 \mathrm{~cm}^{-1}$. This can occur because the $\mathrm{KOH}$ vapor at high temperatures with longer activation time will break down into hydrogen radicals $(\mathrm{H})$ and hydroxyl $(\mathrm{OH})$ to enable reaction with the carbon atoms that can increase the concentration of $\mathrm{OH}$. This is in accordance that during the carbonization process of change in functional group followed by the formation of a new reaction. The results of XRD analysis of activated carbon are shown in Figure 3.

Based on Figure 3, the distance between the aromatic layers of activated carbon with the activation of activator $\mathrm{KOH}$ is not likely to differ, although increased temperature and time of activation. The higher the temperature and duration of activation tends to cause inter-layer height and width of the lower aromatic. In addition, the aromatic layers tend to increase at the activation temperature of 60 minutes. This illustrates that shrinkage in the structure of active carbon crystallites in the direction orderly so that the degree crystallinity tend to increase. These results are consistent with [18] who obtain the degree of crystallinity increases due to the increase in activation temperature.

The figure 4 below shows the result of SEM analysis of activated carbon that activated using $\mathrm{KOH} 1.0 \mathrm{M}$.

Based on Figure 4 is known that the topography of the surface showed a tendency to increase the number and diameter of pores, either due to increased temperature and activation time. These results tend to differ with activated carbon activation by heat, which have the highest pore diameter at $800^{\circ} \mathrm{C}$ temperature treatment and time of activation for 120 minutes. In this activation increased ash content due to decomposition of the surface, probably due to the continuous provision of water vapor at a temperature of $800^{\circ} \mathrm{C}$, so tend to break down water molecules into hydrogen and hydroxyl radicals are highly reactive and react with functionalfunctional groups on the charcoal, causing a shift in the IR absorption (Figure 2). 


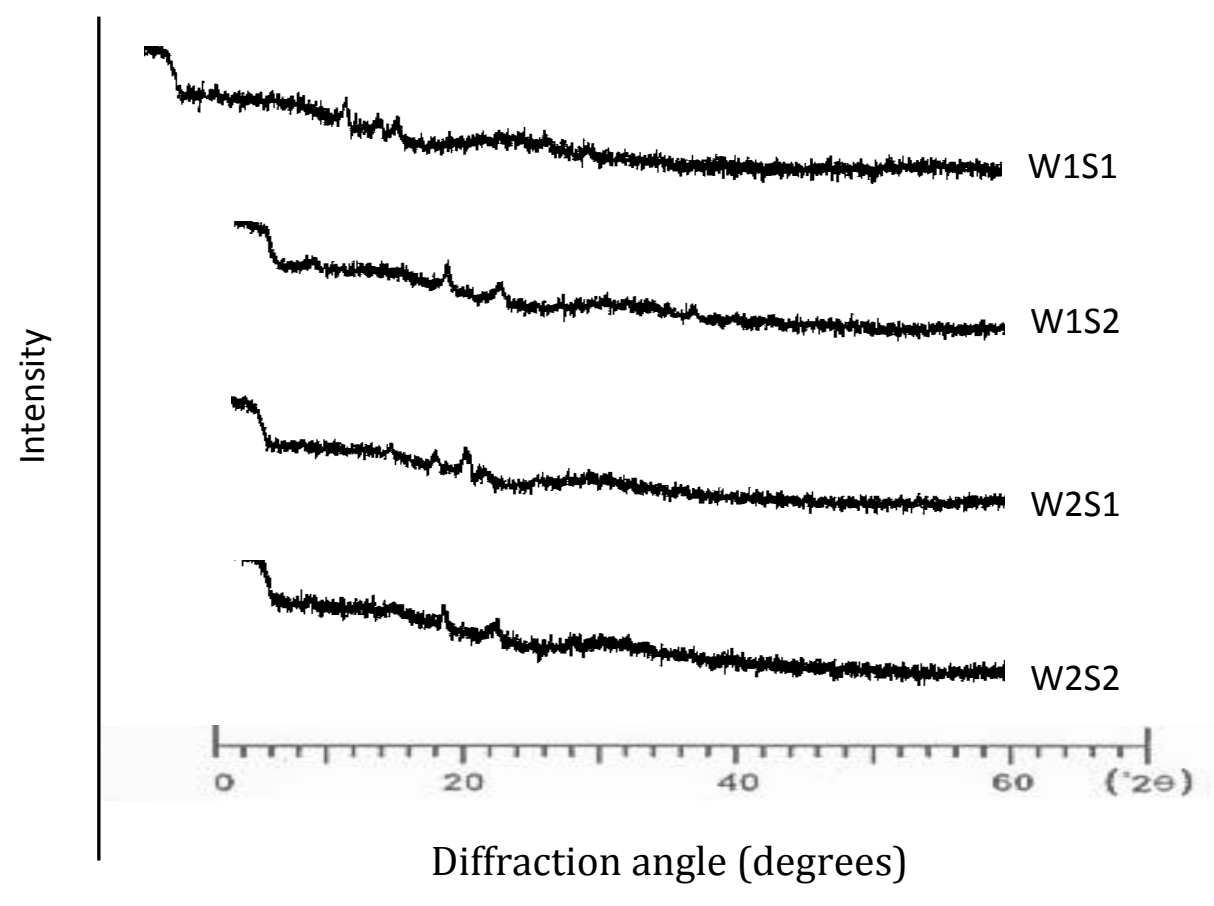

Figure 3. diffractograms of charcoal activation results using $\mathrm{KOH} 1.0 \mathrm{M}$

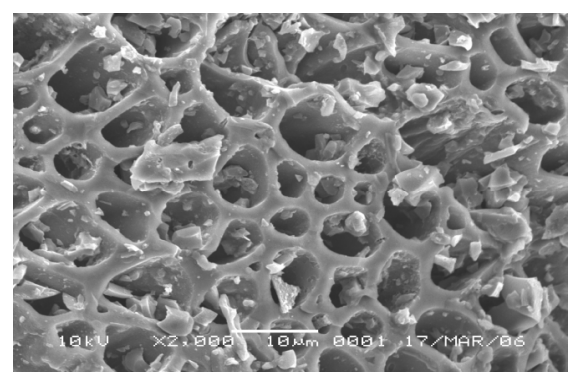

W1S1

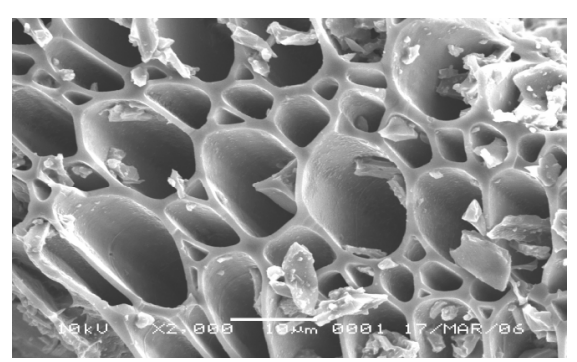

W1S2

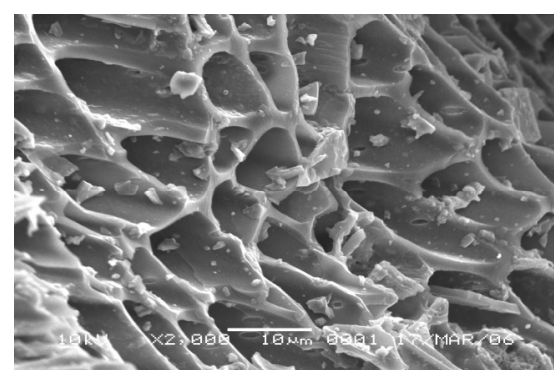

W2S1

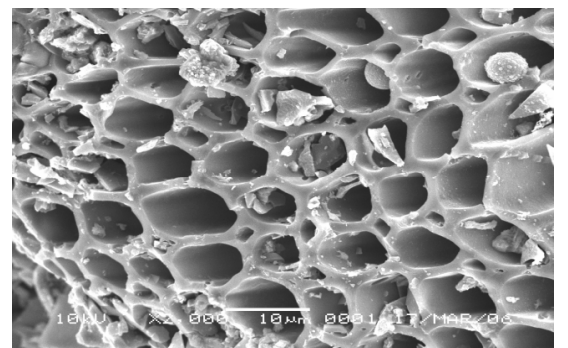

W2S2

Figure 4. Topography of the surface of activated carbon using KOH 1.0 M activator

\section{The Quality of Activated Carbon}

Activated carbon has gained general physical appearance of the same color and shape with the charcoal as raw material. Quality of activated carbon is very dependent on the yield, basic properties, sorption capacity and structure.

\section{Yield}

The yield of activated carbon produced in these experiments ranged from 72.04 to $82.75 \%$.It tends to increase with increasing temperature and the duration of activation. The low yield resulted in general is caused by a chemical reaction occurs between the carbon with $\mathrm{KOH}$ 1.0 M. Extraction rates increased with increasing temperature and activation time, so the carbon that reacts to gaseous $\mathrm{CO}_{2}$ and $\mathrm{H}_{2} \mathrm{O}$ in units of time more and 
more, otherwise the resulting carbon content lower. These results are relatively similar to those performed which made charcoal from coconut shell and raw materials using mangrove wood with $\mathrm{KOH} 1.0 \mathrm{M}$ activator at $500-900^{\circ} \mathrm{C}$ temperature and time of $10-50$ minutes [11].
Characteristics of the basic properties of activated carbon

Quality of activated carbon produced in a process can be detected through the analysis of basic properties that include water content, substance fly, ash, carbon bound, the power of sorption of iodine and benzene. Data from the characterization of the basic properties of activated carbon are presented in Table 2 .

Table 2. Characteristics of the basic properties of activated carbon with $\mathrm{KOH} 1.0 \mathrm{M}$ activator

\begin{tabular}{ccccc|cc}
\hline \multirow{2}{*}{ Treatment } & \multicolumn{3}{c|}{ Percentage (\%) } & \multicolumn{2}{c}{ Adsorption ability } \\
\cline { 2 - 7 } & Water & $\begin{array}{c}\text { Flying } \\
\text { component }\end{array}$ & Ash & Fixed carbon & Iodine(mg/g) & Benzene(\%) \\
W1S1 & 1.45 & 16.13 & 26.25 & 57.62 & 323.25 & 5.46 \\
W1S2 & 1.11 & 13.68 & 26.53 & 59.79 & 327.17 & 8.17 \\
W2S1 & 4.82 & 17.34 & 20.36 & 62.31 & 309.32 & 11.87 \\
W2S2 & 5.41 & 17.27 & 26.59 & 56.14 & 409.52 & 14.03 \\
\hline SNI & $\leq 15$ & $\leq 25$ & $\leq 10$ & $\geq 65$ & $\geq 750$ & $\geq 25$ \\
\hline
\end{tabular}

\section{Water content}

Activated carbon water content ranged from 1.11 to $5.41 \%$ resulted (Table 2), these values meet the requirements of SNI-06-3730-1995 [2] This result is still better when compared with the water content of bark charcoal Acacia mangium, ie 8.39 to $15.19 \%$ [16]. The water content contained in the activated carbon is influenced by the amount of water vapor in the air, while cooling, grinding and sieving [4].

\section{Flying subtances}

The flying substances of produced charcoal ranged from 13.68 to $17.34 \%$ (Table 2). Flying substance content of activated carbon is compliant with ISO-06-3730-1995 [2] since the levels are less than $25.00 \%$. High levels of these substances showed flying surface of activated carbon was still attached to non-carbon Compound fly and also substances originating from the interaction of carbon with water vapor as evidenced by the results of the identification of functional groups by FTIR (Figure 2) and by SEM (Figure 4).

\section{Ash content}

Activated carbon ash content ranged from 20.36 to $26.59 \%$ resulted (Table 2 ). This value is generally is not filled the requirements of SNI-06-3730-1995 [2] because it exceeds the maximum ash content must be less than $10.00 \%$. Actually, the high ash content on an activated carbon is caused by oxidation reactions.

\section{Fixed carbon content}

Fixed carbon content ranged from 56.14 to $62.31 \%$ (Table 2). Fixed carbon of activated carbon is compliant with ISO-06-3730-1995 [2] because of its purity exceeding $65.00 \%$.

Iodine sorption power
Activated carbon iodine sorption power ranged from 309.52 to $409.52 \mathrm{mg} / \mathrm{g}$ (Table 2). Only activated carbon at $800^{\circ} \mathrm{C}$ which meet the requirements of SNI-06-37301995 [2], because the minimum limit of sorption capacity of activated carbon to the solution of iodine is 750.00 $\mathrm{mg} / \mathrm{g}$. However, The higher the temperature the greater activation of sorption capacity of activated carbon.

\section{Benzene sorption power}

Benzene sorption power of activated carbon ranged from 5.46 to $14.03 \%$ (Table 2). The value of sorption capacity of activated carbon to benzene vapor do not exist that meets the requirements of SNI-06-3730-1995 [2], because the minimum threshold limit of $25.00 \%$. The low power of steam activated carbon sorption of benzene shows that still have a non-carbon compound attached to the surface of activated carbon mainly hydrogen and oxygen atoms so that its surface is more non-polar.

\section{Conclusion}

Activated carbon produced in all treatment groups were identified in the FTIR spectrum function,like $\mathrm{OH}, \mathrm{CH}$ and $\mathrm{CO}$ alifatis ether. Activated carbon produced in all treatments showed no significant difference in the degree and distance between the layers of crystallites. The pattern of activated carbon surface topography structure shows that the greater the pore formation in accordance with the temperature increase and the more activation time. The yield of activated carbon ranged from 52.75 to $57.60 \%$. The results of characterization properties of activated carbon was obtained from 1.11 to $5.41 \%$ water, 13.68 to $17.34 \%$ substance fly, 20.36 to $26.59 \%$ ash, and 56.14 to $62.31 \%$ of fixed carbon. Power activated carbon sorption was good enough obtained at $800^{\circ} \mathrm{C}$ temperature treatment and time of activation for 120 minutes that is equal to $409.52 \mathrm{mg} / \mathrm{g}$ of iodine and $14.03 \%(\mathrm{w} / \mathrm{v})$ of benzene. Activated carbon produced has 
less good quality, because only the water content and flying substances that meet the standards.

\section{Acknowledgments}

The authors express thanks to DP2M DIKTI for research funding through the research project Competitive Grant and Research Institute Kuala University and all parties that have supported the success of this research.

\section{References}

[1] Basumatary, B., Dutta, P., Prasad, M. and Srinivasan, K.. 2005. Thermal modeling of active carbon based adsorptive natural gas storage system. Carbon 43(3):541-549

[2] National Standard Agency. 1995. Technical activated carbon, SNI 063730-95. Jakarta

[3] Demirbas, A. 2005. Pyrolysis of ground beech wood in irregular heating rate conditions. Journal of Analytical and Applied Pyrolysis 73:39-43.

[4] El-Hendaway, A.N. 2003. Influence of $\mathrm{HNO}_{3}$ oxidation on the structure and adsorptive properties of corncob-based activated carbon. Carbon 41(4):713-722.

[5] Figueroa-Torres, M.Z., A. Robau-Sanchez, L.D.I. Torre-Saenz, and A Aguilar-Elguezabal. 2007. Hydrogen adsorption by nanostructured carbons synthesized by chemical activation. Microporous and Mesoporous Materials 98:89-93

[6] Gaier, J.R., N.F. Ditmars, and A.R. Dillon. 2005. Aqueous electrochemical intercalation of bromine into graphite fibers. Carbon 43:189-193.

[7] Gomez-Serrano, V., E.M. Cuerda-Correa, M.C. Fernandez-Gonzalez, M.F. Alexandre-Franco, and A. Macias-Garcia. 2005. Preparation of activated carbons from chestnut wood by phosphoric acid chemical activation. Study of microporosity and fractal dimension. Material Letters 59(7):846-853.

[8] Gomez-Serrano, V., M.C. Fernandez-Gonzales, M.L. Rojas-Cervantes, M.F. Alexandre-Franco, and A. Macias-Garcia. 2003. Carbonization and demineralization of coals: a study by means of FT-IR spectroscopy. Bulletin Material Science 26(7):721-732.

[9] Guo, J., and A.C. Lua. 2000. Preparation and characterization of adsorbents from oil palm fruit solid wastes. Journal of Oil Palm Research 12(1):64-70.
[10] Guo, J., Y. Luo, A.C. Lua, R.A. Chi, Y.L. Chen, X.T. Bao, and S.X. Xiang 2007. Adsorption of hydrogen sulphide $\left(\mathrm{H}_{2} \mathrm{~S}\right)$ by activated carbons derived from oil-palm shell. Carbon 45:330-336

[11] Hartoyo and Pari, G. 1993. Increasing the yield and active charcoal absorption by chemical and gasification. Forest Products Research Bulletin 11(5):205-208.

[12] Hayashi, J., N. Yamamoto, T. Horikawa, K. Muroyama, and V.G. Gomes. 2005. Preparation and characterization of high-specificsurface-area activated carbons from $\mathrm{K}_{2} \mathrm{CO}_{3}$-treated waste polyurethane. Journal of Colloids Interface Science 281(2):437443.

[13] Machnikowski, J., Grzyb, B., Machnikowska, H. and Weber, J.V. 2005. Surface chemistry of porous carbons from N-polymers and their blends with pitch. Microporous and Mesoporous Materials. in press.

[14] Maroto-Valer, M.M., Y. Zhang, E.J. Granite, Z. Tang, and H.W. Pennline. 2005. Effect of porous structure and surface functionality on the mercury capacity of a fly ash carbon and its activated sample. Fuel 84:105-108.

[15] Manocha, S. 2003. Porous carbon. Sadhana 28(1-2):335-348.

[16] Pari, G., Hendra, D. and Pasaribu, R.A. 2008. Improved quality activated carbon mangium bark. Forest Products Research Journal 20(3):214-225

[17] Rangel-Mendez, J.R., and Cannon, F.S. 2005. Improved activated carbon by thermal treatment in methane and steam: Physicochemical influences on MIB sorption capacity. Carbon 43(3):467-479

[18] Schukin, L.I., M.V. Kornnievin, R.S. Vartapetjan, and S.I. Beznisko. 2002. Low temperature plasma oxidation of activated carbons. Carbon 40:2021-2040

[19] Stavropoulos, G.G., and A.A. Zabaniotou. 2005. Production and characterization of activated carbons from olive-seed waste residue. Microporous and Mesoporous Materials 82:79-85

[20] Takagi, H., H. Hatori, Y. Yamada, S. Matsuo, and M. Shiraishi. 2004. Hydrogen adsorption properties of activated carbons with modified surfaces. Journal of Alloys and Compounds 385(1-2):257263.

[21] Zhang, F.S., J.O. Nriagu, and H. Itoh. 2005. Mercuri removal from water using activated carbons derived from organic sewage sludge. Water Research 39(2-3):389-395. 